Supporting Information for

\title{
Self-Assembly of One-Dimensional Nanocrystal Superlattice Chains Mediated by Molecular Clusters
}

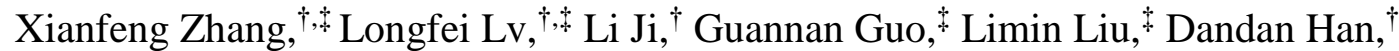
Biwei Wang, ${ }^{\dagger}$ Yaqi Tu, ${ }^{\dagger}$ Jianhua Hu, ${ }^{\dagger}$ Dong Yang, ${ }^{*}, *$ and Angang Dong $*, \dagger$

${ }^{\dagger}$ Collaborative Innovation Center of Chemistry for Energy Materials, Shanghai Key Laboratory of Molecular Catalysis and Innovative Materials, and Department of Chemistry, Fudan University, Shanghai 200433, China

State Key Laboratory of Molecular Engineering of Polymers and Department of Macromolecular Science, Fudan University, Shanghai 200433, China 


\section{METHODS}

Materials. Oleic acid (OA, 90\%), oleylamine (OAm, 70\%), trioctylphosphine (TOP, 97\%), and 1-octadecene (ODE, 90\%) were purchased from Aldrich. Lead oxide (PbO, 99.999\%), lead chloride $\left(\mathrm{PbCl}_{2}, 99.999 \%\right)$, sulfur (99.999\%), tetrabutylammonium hydrogen sulfate (TBAHS, 98\%), iron chloride hexahydrate $\left(\mathrm{FeCl}_{3} \cdot 6 \mathrm{H}_{2} \mathrm{O}, 99 \%\right)$, silver nitrate $\left(\mathrm{AgNO}_{3}, 99.999 \%\right)$, cadmium acetate dehydrate $\left(\mathrm{Cd}(\mathrm{OAc})_{2} \cdot 2 \mathrm{H}_{2} \mathrm{O}, 99.99 \%\right)$, and selenourea $(99.9 \%)$ were purchased form Aladdin. Sodium oleate $(>97.0 \%)$ and tetrabutylammonium bromide (TBAB, >99.0\%) were obtained from TCI. Trichlorogold hydrate hydrochloride $\left(\mathrm{HAuCl}_{4} \cdot 4 \mathrm{H}_{2} \mathrm{O}\right)$ was purchased from Sinopharm. All chemicals were used as received without further purification.

Synthesis of $\mathrm{PbSO}_{4}$ clusters. The OAm-ligated $\mathrm{PbSO}_{4}$ clusters were synthesized by reaction of lead chloride $\left(\mathrm{PbCl}_{2}\right)$ or lead oleate with a number of alkyl-ammonium sulfate compounds such as TBAHS and oleylammonium sulfate $\left(\mathrm{OAm} \cdot \mathrm{H}_{2} \mathrm{SO}_{4}\right)$ at room temperature. A stock solution of $\mathrm{PbCl}_{2}$ was prepared by mixing $139 \mathrm{mg}$ of $\mathrm{PbCl}_{2}(0.5$ $\mathrm{mmol})$ in OAm $(8 \mathrm{~mL})$ at room temperature, followed by heating of the mixture at 150 ${ }^{\circ} \mathrm{C}$ under $\mathrm{N}_{2}$ for $1 \mathrm{~h}$ to form a clear solution $(0.0625 \mathrm{M})$. A stock solution of TBAHS was prepared by dissolving $424.4 \mathrm{mg}$ of TBAHS $(1.25 \mathrm{mmol})$ in $10 \mathrm{~mL}$ of acetone $(0.125 \mathrm{M})$. A stock solution of oleylammonium sulfate was prepared by the direct reaction of $\mathrm{OAm}$ with $\mathrm{H}_{2} \mathrm{SO}_{4}$ with vigorous stirring and the resulting white precipitate was dissolved in acetone to form a clear solution. In a typical procedure to synthesize $\mathrm{PbSO}_{4}$ clusters from $\mathrm{PbCl}_{2}$ and TBAHS, $0.4 \mathrm{~mL}$ of $\mathrm{PbCl}_{2}$ stock solution, $0.2 \mathrm{~mL}$ of TBAHS stock solution, and $0.4 \mathrm{~mL}$ of OA were mixed in $10 \mathrm{~mL}$ of chloroform in a vial, and the resulting mixture was stirred at room temperature for $10 \mathrm{~min}$, yielding a clear colorless solution. The subsequent addition of $30 \mathrm{~mL}$ of ethanol led to a white cloudy suspension, suggesting the formation of $\mathrm{PbSO}_{4}$ clusters. The as-synthesized $\mathrm{PbSO}_{4}$ clusters were separated by centrifugation (5000 rpm, $3 \mathrm{~min}$ ) and the resulting white precipitate was redispersed in $2.5 \mathrm{~mL}$ of chloroform to form a clear colorless solution with a concentration of $\sim 0.01 \mathrm{M}$. A photograph of $\mathrm{PbSO}_{4}$ clusters dispersed in chloroform was shown on the right. It should be noted that although the precise symmetry and structure of $\mathrm{PbSO}_{4}$ clusters could not be determined due to the difficulty to prepare single crystals, the empirical formula of $\mathrm{PbSO}_{4}$ clusters was determined to be $\left[\left(\mathrm{PbSO}_{4}\right)_{6} \cdot(\mathrm{OAm})_{6}\right]$ by various characterization techniques (see Figure S1 for characterization details).

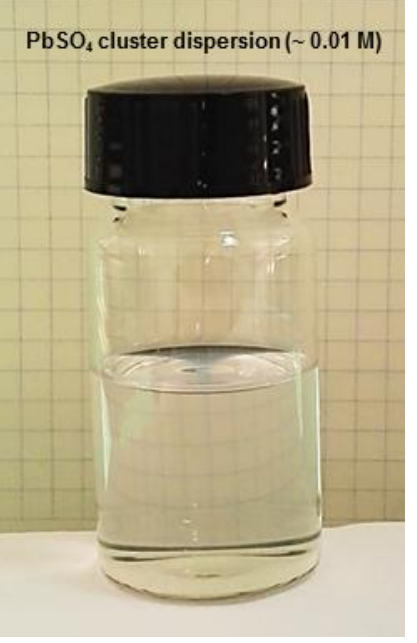

Synthesis of $(\mathbf{C d S e})_{13}$ clusters. The OAm-ligated $(\mathrm{CdSe})_{13}$ clusters were synthesized by a method developed by Buhro and coworkers (Ref. S1). In a typical synthesis, 65 $\mathrm{mg}$ of $\mathrm{Cd}(\mathrm{OAc})_{2} \cdot 2 \mathrm{H}_{2} \mathrm{O}(0.24 \mathrm{mmol})$ was dissolved in $1.5 \mathrm{~g}$ of OAm $(5.6 \mathrm{mmol})$ at 70 ${ }^{\circ} \mathrm{C}$ for $1 \mathrm{~h}$ and cooled to room temperature. After that, $65 \mathrm{mg}$ of selenourea $(0.24 \mathrm{mmol})$ dissolved in $6.8 \mathrm{~g}$ of OAm $(0.025 \mathrm{~mol})$ was injected into the $\mathrm{Cd}(\mathrm{OAc})_{2}$ solution. The mixture was kept still for 2 days and TOP $(65 \mathrm{mg})$ was added to remove the excess 
selenium. The precipitate was separated by centrifugation and washed 3 times with an OAm solution ( $20 \% \mathrm{w} / \mathrm{w}$ in toluene).

Synthesis of colloidal NCs. All preparative procedures were conducted using standard Schlenk-line techniques under nitrogen atmosphere.

$\mathrm{Fe}_{3} \mathrm{O}_{4} \mathrm{NCs}$ with a diameter of $\sim 15 \mathrm{~nm}$ were synthesized according to a modified literature method (Ref. S2). In a typical synthesis, iron oleate $(0.8 \mathrm{~mol}, 72 \mathrm{~g})$ and OA $(11.4 \mathrm{~g})$ were dissolved in ODE (400 g) in a three-neck flask and heated at $320^{\circ} \mathrm{C}$ for 1 h. After cooling down to room temperature, ethanol and isopropanol were added to precipitate $\mathrm{Fe}_{3} \mathrm{O}_{4}$ NCs. The precipitated NCs were redispersed in hexane to form a stable colloidal solution with a concentration of $\sim 10 \mathrm{mg} \mathrm{mL}^{-1}$.

Au NCs with a diameter of $\sim 7 \mathrm{~nm}$ were synthesized by a literature method (Ref. S3). In a typical synthesis, $103 \mathrm{mg}$ of $\mathrm{HAuCl}_{4} \cdot 4 \mathrm{H}_{2} \mathrm{O}(0.25 \mathrm{mmol})$ and $11 \mathrm{~mL}$ of OAm were added into $11 \mathrm{~mL}$ of toluene, and the resulting solution was stirred at $15{ }^{\circ} \mathrm{C}$ for $10 \mathrm{~min}$. After that, a solution containing $22 \mathrm{mg}$ of TBAB $(0.25 \mathrm{mmol}), 1 \mathrm{~mL}$ of OAm, and 1 $\mathrm{mL}$ of hexane was injected and the reaction was allowed to proceed for $1 \mathrm{~h}$. Ethanol was added to precipitate Au NCs, and the precipitated NCs were redispersed in hexane to form a stable colloidal solution with a concentration of $\sim 8 \mathrm{mg} \mathrm{mL}^{-1}$.

Ag NCs with a diameter of $\sim 14 \mathrm{~nm}$ were synthesized according to a modified literature method (Ref. S4). In a typical synthesis, $169.9 \mathrm{mg}$ of $\mathrm{AgNO}_{3}(1 \mathrm{mmol})$ and $20 \mathrm{~mL}$ of OAm were first heated at $60{ }^{\circ} \mathrm{C}$ for $1 \mathrm{~h}$ and then quickly heated up to $240{ }^{\circ} \mathrm{C}$ and maintained at this temperature for $1 \mathrm{~h}$. Acetone was added to precipitate Ag NCs. A size-selective precipitation procedure was used to improve the size uniformity, and the resulting relatively monodisperse $\mathrm{Ag}$ NCs were redispersed in hexane to form a stable colloidal solution with a concentration of $\sim 8 \mathrm{mg} \mathrm{mL}^{-1}$.

PbS nanocubes with an average side length of $\sim 13 \mathrm{~nm}$ were synthesized according to a modified literature method (Ref. S5). In a typical synthesis, $0.28 \mathrm{~g}$ of $\mathrm{PbCl}_{2}(1 \mathrm{mmol})$ and $5 \mathrm{~mL}$ of OAm were heated in a three-neck flask at $90{ }^{\circ} \mathrm{C}$ under vacuum, yielding a clear solution. After that, $27 \mathrm{mg}$ of element sulfur $(0.83 \mathrm{mmol})$ dissolved in $2.5 \mathrm{~mL}$ of OAm was injected into the flask at $90{ }^{\circ} \mathrm{C}$. The resulting mixture was then heated at 220 ${ }^{\circ} \mathrm{C}$ for $1 \mathrm{~h}$. After cooling down to room temperature, ethanol was added to precipitate $\mathrm{PbS}$ nanocubes, which were redispersed in hexane to form a stable colloidal solution with a concentration of $\sim 10 \mathrm{mg} \mathrm{mL}^{-1}$.

$\mathrm{CsPbBr}_{3}$ nanocubes with an average side length of $\sim 11 \mathrm{~nm}$ were synthesized according to a literature method (Ref. S6). In a typical procedure, $\mathrm{Cs}_{2} \mathrm{CO}_{3}(0.814 \mathrm{~g})$ was degassed in ODE $(40 \mathrm{~mL})$ and OA $(2.5 \mathrm{~mL})$ at $120^{\circ} \mathrm{C}$ for $1 \mathrm{~h}$ to obtain the Csoleate solution $(0.125 \mathrm{mM})$. Then $\mathrm{ODE}(5 \mathrm{~mL})$ and $\mathrm{PbBr}_{2}(0.188 \mathrm{mmol}, 69 \mathrm{mg})$ were loaded into a 3-neck flask and dried under vacuum at $120^{\circ} \mathrm{C}$ for $1 \mathrm{~h}$. After that, dried $\mathrm{OAm}(0.5 \mathrm{~mL})$ and $\mathrm{OA}(0.5 \mathrm{~mL})$ were injected into the flask at $120^{\circ} \mathrm{C}$. When the $\mathrm{PbBr}_{2}$ 
salt was completely dissolved, the temperature was raised to $170{ }^{\circ} \mathrm{C}$ and $0.4 \mathrm{~mL}$ of the Cs-oleate solution was quickly injected. The reaction mixture was cooled by an icewater bath. The crude solution was purified via centrifugation (12000 rpm, $3 \mathrm{~min}$ ), and the precipitated nanocubes were redispersed in hexane to form a stable colloidal solution with a concentration $\sim 10 \mathrm{mg} \mathrm{mL}^{-1}$.

Self-assembly of 1D NC superlattice chains. In general, the linear assembly of colloidal NCs was realized by introducing $\mathrm{PbSO}_{4}$ clusters into a hexane solution containing $\mathrm{NCs}$ followed by incubation under ambient conditions. In a typical procedure to assemble $\mathrm{Fe}_{3} \mathrm{O}_{4} \mathrm{NC}$ chains, $\mathrm{PbSO}_{4}$ clusters $(\sim 0.025 \mathrm{mmol})$ were added into $2 \mathrm{~mL}$ of $\mathrm{Fe}_{3} \mathrm{O}_{4} \mathrm{NC}$ solution in hexane, and the resulting mixture was incubated without stirring for a certain period of time. The chain growth process could be completed within 30 min upon the addition of a small amount of OAm $(\sim 0.5 \mathrm{~mL})$. The as-assembled $\mathrm{NC}$ chains isolated by centrifugation were re-dispersed in hexane for further characterization. Linear assembly of other types of NCs was conducted similarly to $\mathrm{Fe}_{3} \mathrm{O}_{4}$ NCs.

Instrument. TEM and HRTEM images were obtained using a Tecnai G2 F20 S-TWIN microscope operated at $200 \mathrm{kV}$, while HAADF-STEM images and EDS spectra were obtained using a JEOL JEM-ARM200F microscope operated at $300 \mathrm{kV}$. Fouriertransform infrared (FTIR) spectra were collected on a Perkin-Elmer Spectrum Two spectrometer. UV-visible absorption spectra were recorded on a Shimadzu UV-3600 UV-vis-NIR spectrophotometer. Photoluminescence (PL) spectra of $\mathrm{PbSO}_{4}$ clusters were collected on a Shimadzu RF-5301PC spectrofluorophotometer with an excited wavelength of $300 \mathrm{~nm}$. Small-angle XRD was carried out on a Bruker D4 X-ray diffractometer ( $\mathrm{Cu} \mathrm{K \alpha}$ irradiation, $\lambda=1.541 \AA$ ). X-ray photoelectron spectrum (XPS) was acquired using a PHI 5000C ESCA system, and the C 1s peak at $284.6 \mathrm{eV}$ was used as the reference line. Thermogravimetric analysis (TGA) was carried out in air on a Perkin-Elmer Pyris 1 thermogravimetric analyzer with a heating rate of $10{ }^{\circ} \mathrm{C} / \mathrm{min}$. Laser desorption/ionization (LDI) mass spectra were recorded without matrix on an $\mathrm{AB}$ SCIEX 5800 MALDI-TOF mass spectrometer. The samples were prepared by dropcasting $\mathrm{PbSO}_{4}$ cluster solutions in chloroform onto a 384-position stainless-steel LDI plate followed by drying. 

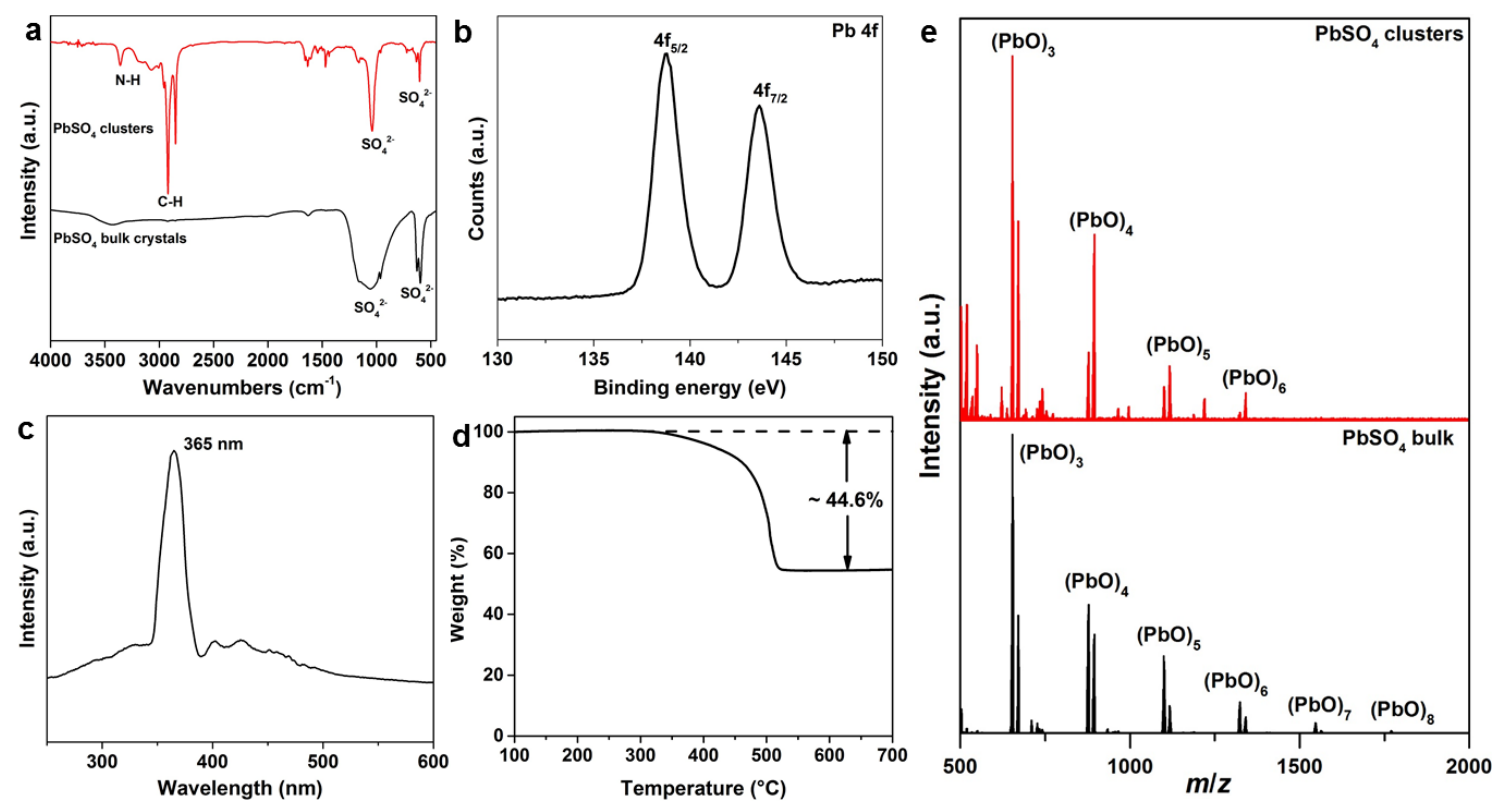

Figure S1. (a) FTIR spectra of $\mathrm{PbSO}_{4}$ clusters and bulk crystals. (b) XPS scan of the $\mathrm{Pb} 4 \mathrm{f}$ signal from $\mathrm{PbSO}_{4}$ clusters. (c) Room-temperature PL spectrum of $\mathrm{PbSO}_{4}$ clusters dispersed in chloroform. (d) TGA curve of $\mathrm{PbSO}_{4}$ clusters. (e) LDI mass spectra of $\mathrm{PbSO}_{4}$ clusters and bulk crystals.

Figure S1a presents the FTIR spectrum of $\mathrm{PbSO}_{4}$ clusters. The intense $\mathrm{C}-\mathrm{H}$ stretching bands at $\sim 2800-3000 \mathrm{~cm}^{-1}$ and N-H stretching bands at $\sim 3068-3360 \mathrm{~cm}^{-1}$ were ascribed to the OAm ligands stabilizing $\mathrm{PbSO}_{4}$ clusters, while the intense bands at $\sim 1050$ and $600 \mathrm{~cm}^{-1}$ were ascribed to the vibrations of $\mathrm{SO}_{4}{ }^{2-}$ (Ref. S7), consistent with $\mathrm{PbSO}_{4}$ bulk crystals. The FTIR results confirmed the existence of OAm and $\mathrm{SO}_{4}{ }^{2-}$ in $\mathrm{PbSO}_{4}$ clusters. Figure $\mathrm{S} 1 \mathrm{~b}$ shows the XPS scan of $\mathrm{PbSO}_{4}$ clusters, in which the $\mathrm{Pb} 4 \mathrm{f}$ signal at 138.8 eV could be attributed to $\mathrm{PbSO}_{4}$, consistent with previous reports (Ref. S8). Figure S1c presents the $\mathrm{PL}$ spectrum of $\mathrm{PbSO}_{4}$ clusters, showing that $\mathrm{PbSO}_{4}$ clusters were optically active, exhibiting a PL peak at $\sim 365 \mathrm{~nm}$, which is in agreement with the previous results based on $\mathrm{PbSO}_{4}$ nanostructures (Ref. S7). Figure S1d shows the TGA profile, which was acquired by heating $\mathrm{PbSO}_{4}$ clusters up to $700{ }^{\circ} \mathrm{C}$ in air. The weight percentage of OAm in clusters was determined to be $\sim 44.6 \mathrm{wt} \%$, suggesting that the stoichiometric ratio between $\mathrm{PbSO}_{4}$ and $\mathrm{OAm}$ was close to $1: 1$. Figure $\mathrm{S} 1 \mathrm{e}$ shows the LDI mass spectrum of $\mathrm{PbSO}_{4}$ clusters, in which $(\mathrm{PbO})_{x}$ was found to be the dominant species as in the bulk. Presumably, $(\mathrm{PbO})_{x}$ species were generated by the fragmentation of $\mathrm{PbSO}_{4}$ clusters under laser excitation. The observed $(\mathrm{PbO})_{6}$ species coupled with FTIR, XPS, $\mathrm{PL}$, and TGA results strongly suggested that $\mathrm{PbSO}_{4}$ clusters possessed a molecular formula of $\left[\left(\mathrm{PbSO}_{4}\right)_{6} \cdot(\mathrm{OAm})_{6}\right]$. 


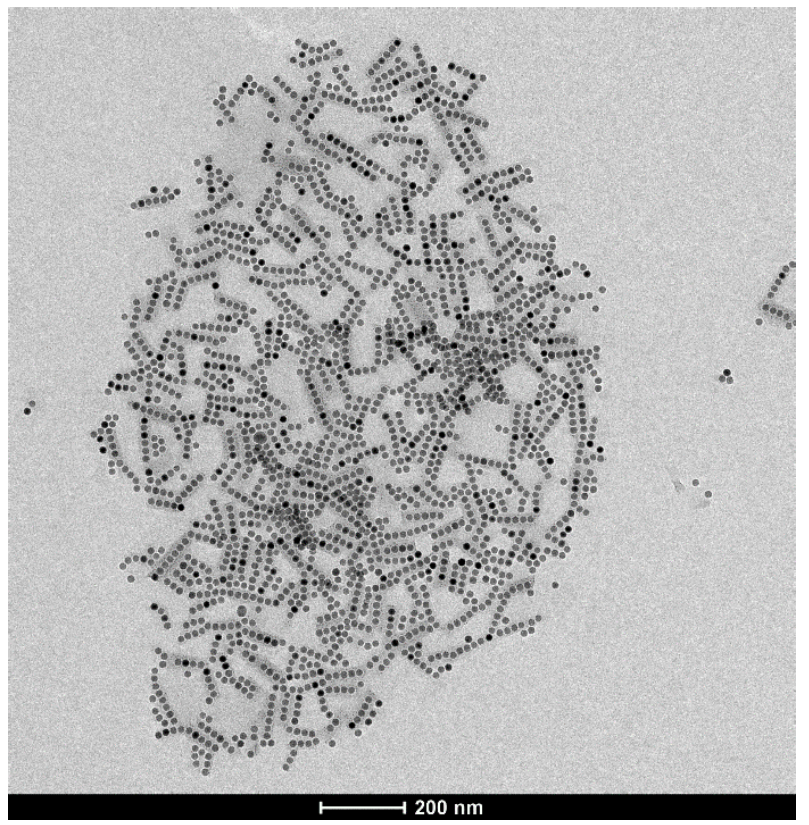

Figure S2. Representative TEM image of short NC chains observed within the first 5 min of incubation.
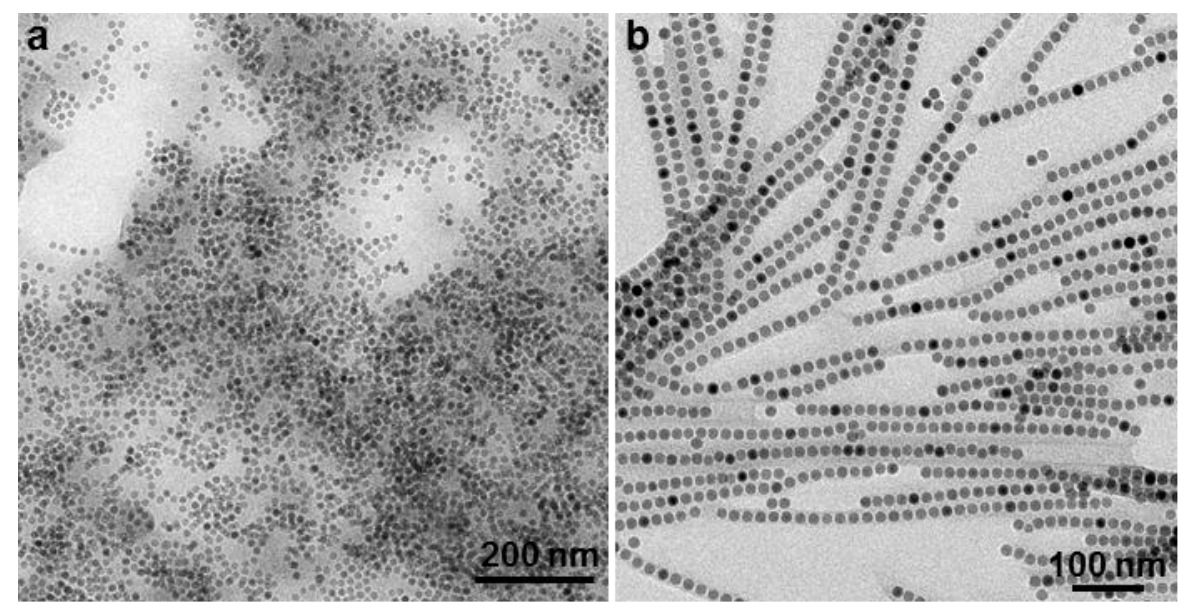

Figure S3. (a) TEM image of $\mathrm{Fe}_{3} \mathrm{O}_{4} \mathrm{NC}$ and cluster mixtures, which were obtained by dispersing the preformed NC chains in chloroform. (b) TEM image of NC chains reassembled from $\mathrm{Fe}_{3} \mathrm{O}_{4} \mathrm{NC}$ and cluster mixtures shown in (a) when the incubation solvent was switched back to hexane. 

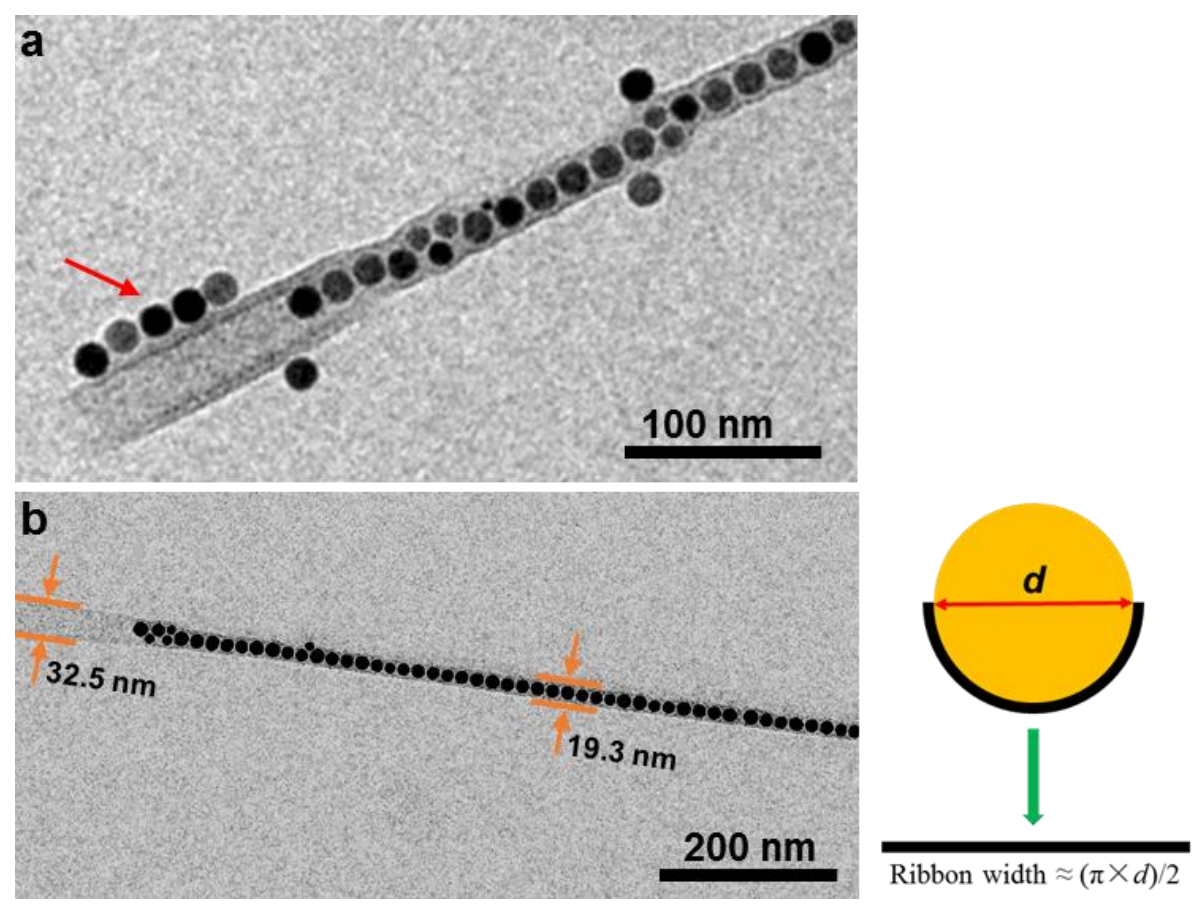

Figure S4. (a) TEM image of $\mathrm{Fe}_{3} \mathrm{O}_{4} \mathrm{NC}$ chains upon vigorous sonication for $10 \mathrm{~min}$. The dislocation of NCs (indicated by the red arrow) shows that the cluster shell possesses a tubular morphology. (b) TEM image of a single $\mathrm{Fe}_{3} \mathrm{O}_{4} \mathrm{NC}$ chain, in which the empty cluster shell completely unrolled to form a flat ribbon with a width of $\sim 32.5$ $\mathrm{nm}$. Considering that the diameter $(d)$ of $\mathrm{Fe}_{3} \mathrm{O}_{4} \mathrm{NCs}$ with two monolayers of OA is $19.3 \mathrm{~nm}$, complete encapsulation of $\mathrm{NC}$ arrays requires a ribbon having a width of $60.6 \mathrm{~nm}$ (ribbon width $\approx \pi \times d)$, which is about two times of the ribbon width $(\sim 32.5$ $\mathrm{nm})$ observed. Therefore, the original cluster shell should resemble a half cylinder, with approximately half of NC surfaces exposed, as schematically illustrated on the right. 

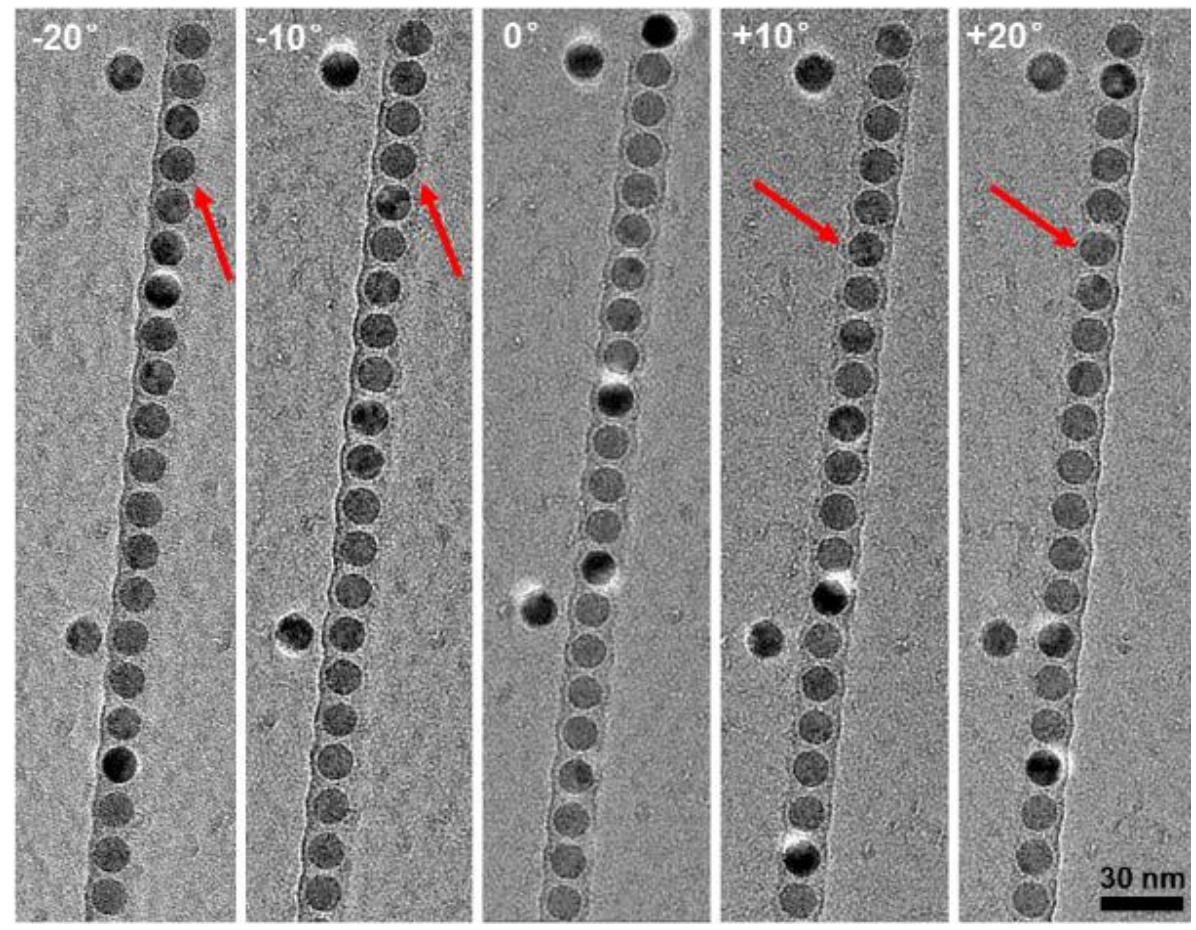

Figure S5. TEM images of a single $\mathrm{Fe}_{3} \mathrm{O}_{4} \mathrm{NC}$ chain acquired at different tilting angles. As indicated by the red arrows, the right (or left) side wall of the cluster shell gradually disappeared as the TEM grid was tilted from $0^{\circ}$ to $-10^{\circ}$ and $-20^{\circ}$ (or $10^{\circ}$ and $20^{\circ}$ ), suggesting that $\mathrm{NC}$ chains exhibit structural anisotropy across the chain width. 


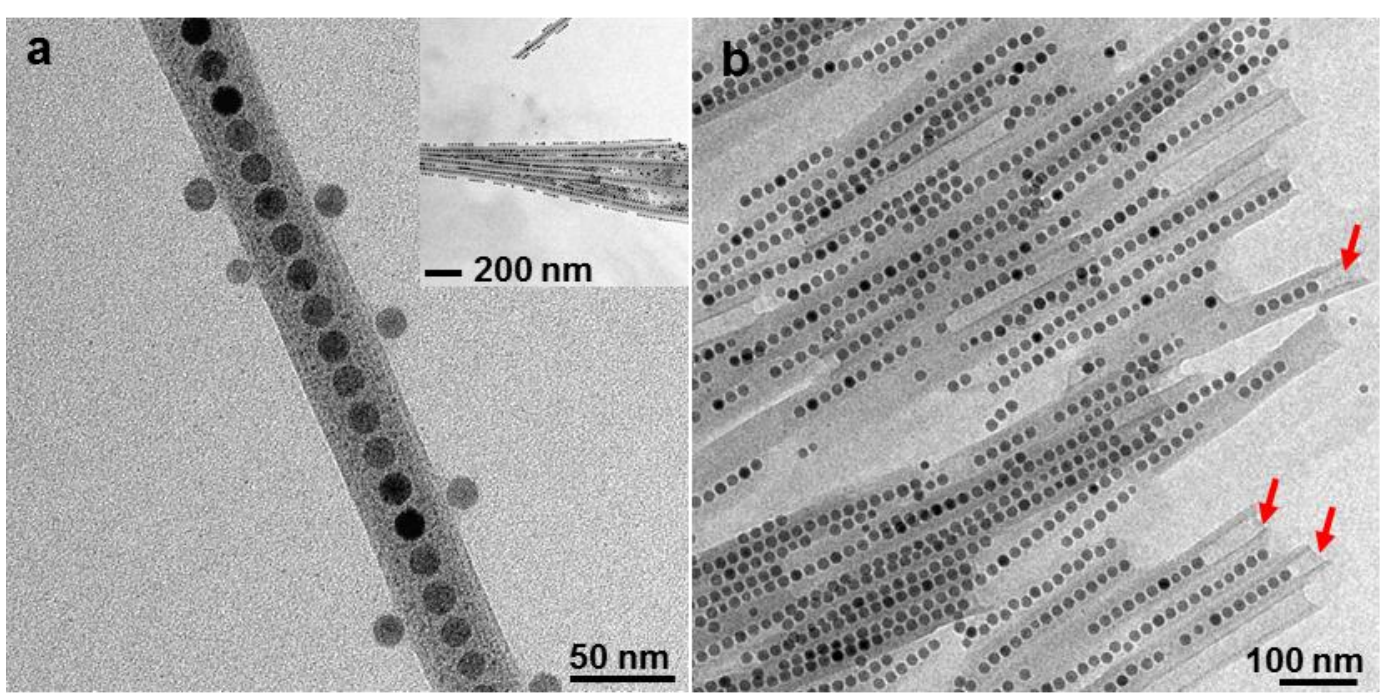

Figure S6. (a) TEM image of a single $\mathrm{Fe}_{3} \mathrm{O}_{4} \mathrm{NC}$ chain with a thicker cluster shell, which was obtained by doubling the cluster concentration under otherwise identical conditions. The inset shows a low-magnification TEM image. (b) TEM image of the same sample after sonication ( $10 \mathrm{~min}$ ). The dislocation of the encapsulated $\mathrm{Fe}_{3} \mathrm{O}_{4}$ NCs revealed that the thicker cluster shells were partially opened (indicated by red arrows), suggesting that increasing the cluster concentration did not change the halfcylindrical morphology of cluster shells.
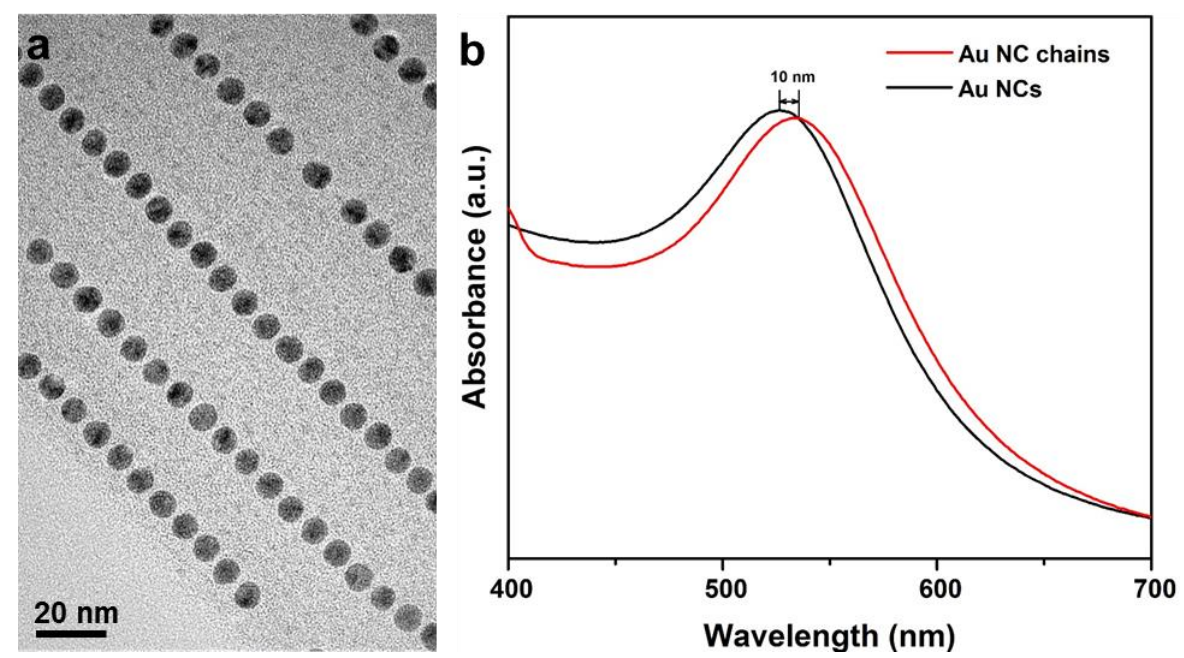

Figure S7. (a) Low-magnification TEM image of Au NC chains. (b) Absorption spectra of $\mathrm{Au} \mathrm{NCs}$ and $\mathrm{Au}$ NC chains. Both samples were dispersed in hexane for measurements. The plasmonic peak of Au NC chains was red-shifted by $\sim 10 \mathrm{~nm}$ relative to that of $\mathrm{Au} \mathrm{NCs}$, primarily attributed to the enhanced interparticle interactions. 

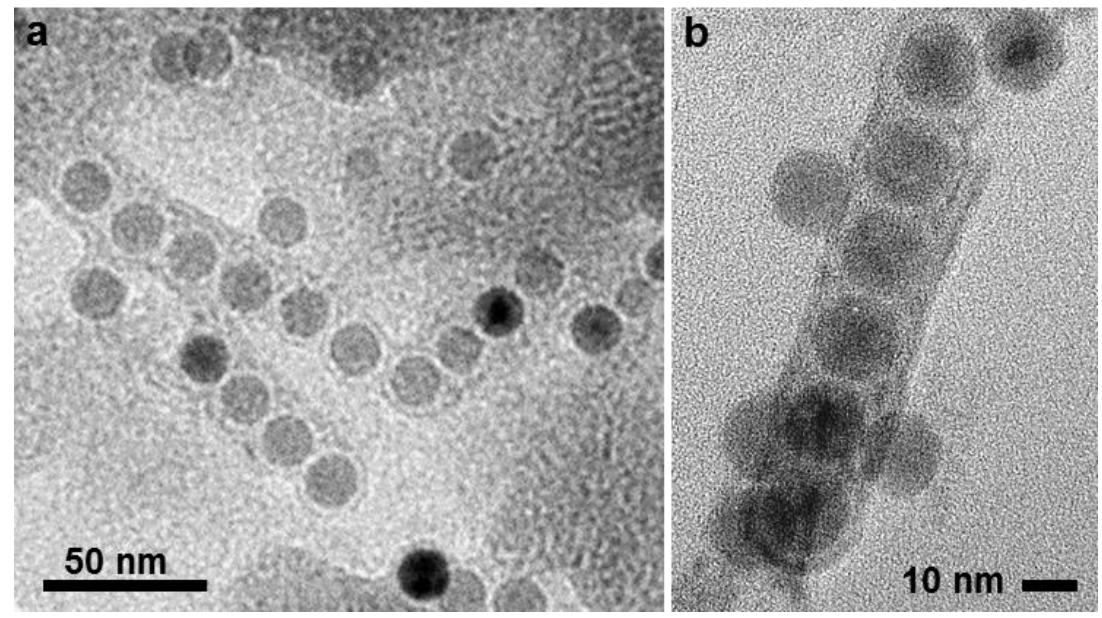

Figure S8. (a, b) Representative TEM images of $\mathrm{Fe}_{3} \mathrm{O}_{4} \mathrm{NC}$ chains self-assembled with the aid of $(\mathrm{CdSe})_{13}$ clusters.
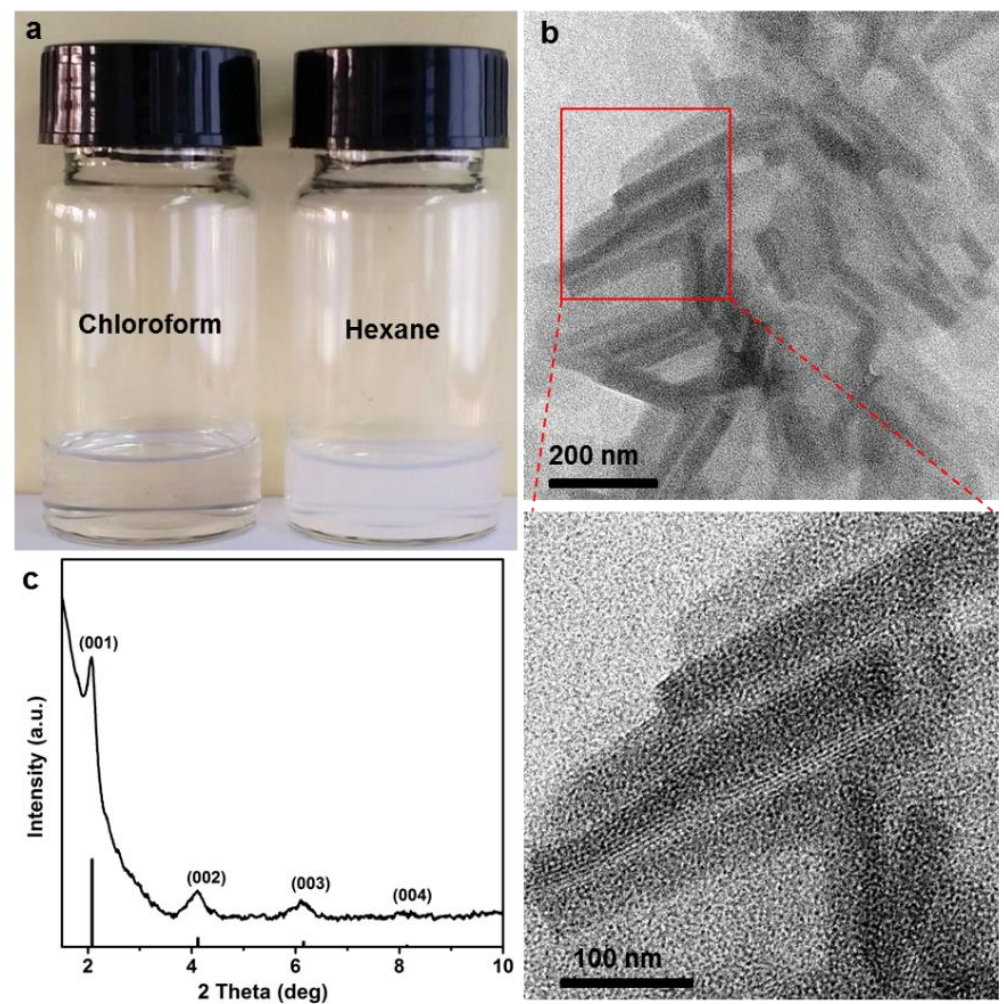

Figure S9. (a) Photographs of $\mathrm{PbSO}_{4}$ clusters dispersed in chloroform (left) and hexane (right). Dispersing $\mathrm{PbSO}_{4}$ clusters in chloroform yielded a clear colorless solution, suggesting that chloroform is a good solvent for $\mathrm{PbSO}_{4}$ clusters. In contrast, dispersing $\mathrm{PbSO}_{4}$ clusters in hexane led to a cloudy suspension with white precipitates, suggesting that hexane is a poor solvent for $\mathrm{PbSO}_{4}$ clusters. (b) TEM images of the precipitate, showing the formation of lamellar ribbons with a dimension of $\sim 400 \times 60 \mathrm{~nm}$. (c) Lowangle XRD pattern of $\mathrm{PbSO}_{4}$ cluster ribbons. The interlayer spacing was determined to be $\sim 4.2 \mathrm{~nm}$, consistent with the two stacking layers of OAm ligands stabilizing $\mathrm{PbSO}_{4}$ clusters (Ref. S1). 


\section{References}

S1. Wang, Y.; Liu, Y.; Zhang, Y.; Kowalski, P. J.; Rohrs, H. W.; Buhro, W. E. Inorg. Chem. 2013, 52, 2933-2938.

S2. Park, J.; An, K. J.; Hwang, Y. S.; Park, J. G.; Noh, H. J.; Kim, J. Y.; Park, J. H.; Hwang, N. M.; Hyeon, T. Nat. Mater. 2004, 3, 891-895.

S3. Wu, B.; Yang, H.; Huang, H.; Chen, G.; Zheng, N. Chin. Chem. Lett. 2013, 24, 457-462.

S4. Peng, S.; McMahon, J. M.; Schatz, G. C.; Gray, S. K.; Sun, Y. Proc. Natl. Acad. Sci. 2010, 107, 14530-14534.

S5. Joo, J.; Na, H. B.; Yu, T.; Yu, J. H.; Kim, Y. W.; Wu, F. X.; Zhang, J. Z.; Hyeon, T. J. Am. Chem. Soc. 2003, 125, 11100-11105.

S6. Protesescu, L.; Yakunin, S.; Bodnarchuk, M. I.; Krieg, F.; Caputo, R.; Hendon, C. H.; Yang, R. X.; Walsh, A.; Kovalenko, M. V. Nano Lett. 2015, 15, 3692-3696.

S7. Deng, B.; Wang, C.; Li, Q.; Xu, A. J. Phys. Chem. C 2009, 113, 18473-18479.

S8. Konstantatos, G.; Levina, L.; Fischer, A.; Sargent, E. H., Nano Lett. 2008, 8, 14461450. 